\title{
TOWARDS ARTIFICIAL INTELLIGENCE. SOCIOLOGICAL REFLECTIONS ON THE RELATIONSHIP MAN - ORGANIZATION - DEVICE
}

doi: $\quad 10.2478 /$ czoto-2019-0116

Date of submission of the article to the Editor: $30 / 11 / 2018$

Date of acceptance of the article by the Editor: 14/01/2019

Małgorzata Suchacka ${ }^{1}$ - orcid id: 0000-0002-3769-5892

Nicole Horáková, M.A. ${ }^{2}$ - orcid id: 0000-0002-1075-053X

${ }^{1}$ University of Silesia in Katowice, Poland, malgorzata.suchacka@us.edu.pl

${ }^{2}$ University of Ostrava, Czech Republic

\begin{abstract}
The main goal of the study will be to pay attention to technologization of the learning process and its social dimensions in the context of artificial intelligence. The reflection will mainly cover selected theories of learning and knowledge management in the organization and its broadly understood environment. Considering the sociological dimensions of these phenomena is supposed to lead to the emphasis on the importance of the security of the human-organization-device relationship. Due to the interdisciplinary nature of the issue, the article will include references to the concept of artificial intelligence and machine learning. Difficult questions will arise around the ideas and will become the conclusion of the considerations.
\end{abstract}

Keywords: artificial intelligence, learning process, innovations.

\section{INTRODUCTION}

Without a doubt, technological innovations and the way of managing them in companies have become a factor intensifying the pace of changes in the contemporary world. Engineers are constantly working on new production methods, developing new materials or manufacturing techniques. The reflection of scientists on the impact of technological novelties on the social life of people as well as individuals does not keep up with the course of events that go down in history faster than ever.

Technical facilities are becoming more and more common and increasingly complicated, at the same time they are becoming an indispensable part of any social environment. People often cannot imagine their lives without technological improvements in their environment. But the question that arises is - when the machine outsmart and overtake the human way of thinking.

Because of the gap between technological progress and the exploration of its impact on the social context, cooperation between technical and social sciences is of paramount importance.

Our contribution raises questions concerning the relationship between man as the technical object and its environment, it relates not only to the ways of learning of a 
man, his reaction, the possibility of a cooperation in a group, but also to a correlation of these factors. The reflections on this topic presented in this article are purely theoretical, and the scope of analysis is based on the literature on selected concepts. The main objective of our study is the indication of the social dimensions of the learning process with a particular emphasis on the process of its technologicalization, which leads to human contact with the increasingly complex form of artificial intelligence. This very fact changes man himself and results in consequences of social nature. Knowledge management in organizations, especially in production companies, is both a reason and a consequence of these effects. Artificial intelligence, which initially supposed to support man in selected tasks, may begin to limit him. And a real revolution will take place when artificial intelligence has completed integrating knowledge of three areas of science that include the laws of matter, life and mind. Conclusions from the analysis are meant to provoke reflection on the direction of science development without the interdisciplinary approach taken into account.

\section{TECHNOLOGIZATION OF THE LEARNING PROCESS AND ITS SOCIAL DIMENSIONS}

The available technologies change the perception of knowledge and learning. In the past, learning was largely understood as memorizing facts. Today, facts and backgrounds are almost always available instantly and everywhere on the smartphone and other mobile devices. As a result, factual knowledge is no longer central to learning and creative approaches gain in importance.

The change of learning through new technologies is taking place on different dimension: it concerns the dimension of content as well as time and methodology. Let us have a closer look at these dimensions: The dimension of content is a basic category and closely linked to the question of the importance of knowledge and learning in a society. More than 20 years ago, Peter F. Drucker stated in his book "Post - Capitalist Society" (1994) a shift to knowledge society: "The basic economic resource [...] is no longer capital nor natural sources [...] nor "labor". It is and will be knowledge." (Drucker, 1994) The value of a society will be produced by innovation and production which are both applications of knowledge, so Drucker. In the knowledge society, the position of the former capitalist will be held by a specialized worker ("knowledge worker") who knows how to apply his knowledge and make it productive. In this new type of society - the post capitalist society - will be neither (manual) work nor capital the main value but knowledge. According to this it will be a social challenge to integrate less skilled workers in a reasonable way into the working process.

Today, changing the world of work through digitization and computerization, known by the term Industry 4.0, is in full swing, affecting all industrial sectors, as well as the administration. Knowledge and skills that are still relevant today will be outdated tomorrow due to accelerated development. In order to maintain the productivity of the knowledge worker - to put it in Drucker's words - despite the technical changes, there are a number of points to consider: first of all, the organization that employs the knowledge workers must provide them with enough free space to further educate and adequately analyse the requirements of their work (Drucker, 1999: 83 - 84). Autonomy, life-long learning and a motivational environment are the key points to keeping the productivity of the knowledge workers at a high level. Industry 4.0 requires 
highly qualified specialists who are able to control processes, lead employees and at the same time have deep technical understanding in order to coordinate the cooperation of man and machine or in this case of man and computer or artificial intelligence. On the one hand, the digital transformation affects each individual, on the other hand, it affects the organizations themselves and the educational institutions alike (kindergarten, school, university). The Federal Association of German Industry (BDI), representing the interests of various branches of industry in Germany, points out that digitization is not a force of nature but a process that is shaped and codetermined by organizations and individuals (BDI, 2016: 11).

The rapid digitization of work processes requires a continuous training of employees, as already mentioned above. Once acquired, knowledge in school and university must be continuously expanded and renewed. The term life-long learning is thus not just a buzzword, but must be filled with content and offers suitable also for older or less qualified employees. In January 2018, the European Commission published an 18point letter of recommendation to help member states better implement the key competences for life-long learning developed in 2006 (European Commission, 2018). These measures are necessary to cushion the ongoing structural change in the labor market and make it socially acceptable. Since "European societies and economies are experiencing significant digital and technological innovations as well as labor market and demographic changes. Many of today's jobs did not exist a decade ago and many new forms of employment will be created in the future." (European Commission, 2018). As the dimension of time includes not only life-long learning and thus a continuous learning process, but also the temporal and local independence of learning processes. A study at a Swiss university shows that the use of learning apps can be an enrichment of the learning culture: These days students prefer different media that complement each other. Learning apps on smartphones do not replace traditional learning media but provide an additional source of learning for students. Thus, new technologies offer the opportunity to educate outside of the traditional classroom, and often these offerings are used in unusual learning situations, such as in a bus or on a platform. However, the study also came to the conclusion that faceto-face teaching is not to be replaced by the new technical possibilities of learning but should only be supplemented, according to the learners' wishes (Glahn et al., 2015).

It seems that despite the increased individualisation of the learning process through the use of technology, no social isolation of the learners is taking place. Because gaining, testing and sharing knowledge are social processes, even under the conditions of the digital era. Social processes refer to the social exchange and the need to build a community (Gemeinschaft). New online learning opportunities and open courses create new communities, integrating learners across temporal and spatial boundaries. For this learning process to succeed, it must be professionally accompanied and moderated. In this context, R. Florida speaks about the special importance of the regions in this learning process. As "learning regions", they provide the infrastructure for the transfer of knowledge in the knowledge society. On a global scale, the infrastructure of the regions determines the success or failure of the learning process at school, at work and for the region itself. (Florida, 1995: 527).

The new technological developments allow the introduction and the use of new learning formats, such as Smart Learning Environments (SLE), Learning Apps, Learning Platforms or open source learning management systems (LMS). These forms rely on mobile devices to support the learning process of mobile people and 
their need for flexibility, independence of space and time, ubiquitous availability of information and knowledge, "seamless" learning, a simple combination of formal and informal learning. The development of mobile technologies and artificial intelligence is transforming mobile learning towards smart learning, which can greatly support lifelong learning through strong personalization and individualization. As a result, the heterogeneous learning needs, different learning biographies and diverse media use interests can be taken into greater consideration and integrated into the learning process (de Witt, 2018: 996). The biggest challenges for the didactic conception (methodological dimension) of smart learning units is the fluent connection of formal (teaching) and informal (home environment) learning spaces, increased learner autonomy and thus the measurability of the learning process, as well as the higher drop-out rate in media-based learning, affecting especially individuals who cannot cope with autonomous forms of learning (Kerres et al., 2002: 4).

Does the outlined technical development in the learning process actually lead to an emancipation and self-realization of the individual within society? Early on, certain critical voices also set in, such as Herbert Marcuse, who already in 1941 published an essay, pointing out that rationality has changed from a critical to an adapted attitude through its use in the technological process: "Rationality is being transformed from a critical force into one of adjustment and compliance. Autonomy of reason loses its meaning in the same measure as the thoughts, feelings and actions of men shaped by the technical requirements of the apparatus which they have themselves created. Reason has found its resting place in the system of standardized control, production and consumption. There it reigns through the laws and mechanisms which insure the efficiency, expediency and coherence of this system." (Marcuse, 1941: 146). To put it briefly, Marcuse found that the technological society is one-dimensional and the potential for truly critical thought leading to a society where human potential can flourish is blocked by the achievements of industrial society (Marcuse: 1964). The freedom and autonomy of the knowledge worker underlined by Drucker, who develop their own responsibility and expand their skills through life-long learning, is often criticized as a neoliberal concept that fetishes skills and conceptualize them "as "things" that can be acquired and measured and that possess an inherent capacity to bring about desired outcomes, outcomes that can be measured in dollars" (Urciuoli, 2008: 212). The skills that today's digitized world of work demands of employees are no longer the so-called "hard skills", i.e. technical know-how, but what is required today are "soft skills", which Michel Foucault calls "technologies of self" (Foucault: 1988). According to Foucault, by educating and developing their (soft) skills, employees demonstrate their willingness to act in accordance with the rules of the existing system, to recognize dominant practices and to be compatible with institutions and beliefs.

\section{THE REFLECTION ABOUT LEARNING AND KNOWLEDGE MANAGEMENT IN THE ORGANIZATION - THEORETICAL BACKGROUND}

An apostle of a new class of educated managers, Peter Drucker claims in his work that the traditional, high importance of the current economic resources such as labor, land and money is gradually decreasing. Profit from these sources is getting smaller and the only one if not the main source of wealth are information and knowledge. "In fact, each of the evolving branches of traditional industry owes its restructuring around knowledge and information." (Drucker, 1999: 149). Knowledge becomes the 
main resource, and employees are the most valuable capital. "In the traditional management system, the most important thing was to convince bored workers to work hard and at an even pace. Today, employees are perceived as the company's most important resources because of the content of their heads." (Micklethwait and Wooldridge, 1996).

The deliberations on this topic carried out by contemporary researchers have led to creating many interesting ideas on how to manage knowledge in the organization and the principles of its circulation [in a broad sense]. In general, it can be said that knowledge management in the broadest sense covers all knowledge aspects that affect the development of the company. "The main problem for knowledge-based management is the conversion of the so-called hidden, personalized knowledge related to the experience and skills, as well as the intuition and values of individuals, in the knowledge that is available, external to individuals and often codified." (Nonaka and Takeuchi, 1995). According to Japanese authors, the knowledge management system is designed properly only when it allows the company to acquire, analyze and use knowledge in order to make faster, smarter and better decisions leading to achieving a competitive advantage. Therefore, a systemic knowledge acquisition is understood as acquiring knowledge in accordance with the knowledge management strategy. (Suchacka and Szczepański, 2006).

One of the most interesting concepts is the proposal of P. Senge, who claims that today's companies owe their advantage to learning skills and the fact that they are constantly using it. In his opinion, "the core of a learning organization is a change in the way of thinking, a transition from perceiving problems as caused by someone or something else to realising that our own actions create problems that we experience. A learning organization is a place where people discover again and again the way they create the reality that surrounds them and how they can change it." (Senge 1990). The structure of such organizations is subordinated to and directed at high indicators of efficiency and economic growth, while at the same time generating the ability to recognize and skilfully adapt to the conditions of the environment, and innovation based on the use of knowledge.

Theoretical concepts of a "learning organization" emphasizing its various aspects are intended to strengthen the way of management, which is called knowledge management. And what is not without significance, it is present also in a much broader context than an organization in a form of a company. New conditions, involving the use of innovative technological solutions, have forced the transfer of all the characteristic features of the company's development into a wider range of impact - for a region. In this way, it has become the region of constant education and learning, the creation of new knowledge and the continuity of consolidation and its transfer. Knowledge and human intelligence will replace manual labor as the main source of value. Technological changes will take place at a pace unknown so far, and innovation will be something permanent and continuous. This will require enormous energy and effort to design the necessary changes. In Poland, to some degree Silesia is such an example as the most industrialized region and undergoing a particular metamorphosis towards the learning region. (Suchacka 2014)

Undoubtedly, the issue of continuous learning is related to the issue of innovation, which was at the center of the researchers' interest. Inventions require various degrees of technical knowledge, analysis and creative intellect. However, the assumption is to create support for human work. Gradually, in the social sciences, an 
approach based on the use of various computational methods and new technologies appeared. All in order to make faster and easier decision-making as regards various groups of people, e.g. employees, clients or voters. These solutions allow using new methods of data acquisition. The most common is the access to digital footprints of human activity, either in social networks, or even by simply analyzing behavior based on the use of mobile phones. With the use of these computational techniques [software?], it is possible to simulate different behaviors. More and more often, people are being replaced by machines, devices, and appropriate software, all through learning specific forms of response based on the output data. Nowadays, the ethical question should be a top priority for scientists, because many people might be really hurt by these algorithms. In addition to interdisciplinary cooperation, taking into account social sciences professionals, the main goal of the researchers should be a permanent indication of good methods of working with such data.

\section{ARTIFICIAL INTELLIGENCE - SUPERVISED AND UNSUPERVISED LEARNING - THE IMPORTANCE OF STRATEGIC APPROACH}

More and more scientists point to the fact that we are at the threshold of a revolution, the source of which is the introduction of artificial intelligence to various areas of socio-economic life. Both researchers and practitioners sensitive to social values point out not only to the need to keeping up with the best economies in the world, but also to creating a comprehensive strategy for the development of artificial intelligence. Such a strategy would include constantly updated implications resulting from interdisciplinary research on the consequences arising from the development of $\mathrm{Al}$ (Artificial Intelligence). Since the 1950s, the term of artificial intelligence has been considered with the omission of the concept of consciousness, which may cause serious threats, but on the other hand, it is necessary to set aside certain social or psychological phenomena. The first widely accepted extended definition of artificial intelligence was introduced by Turing. What it meant to him was the ability to perform cognitive tasks through the machine, so that a man who asks questions, could not recognize that it is the actual machine is responding (Turing 1950). In the test developed by Turing, it was verified how effectively the machine could pretend to be a human during a conversation. Currently, artificial intelligence is an IT department that creates models of intelligent behaviors that can be used in computer programs. The purpose of such programs is to imitate manifestations of human intelligence, such as making decisions under conditions of uncertainty, analysis and synthesis of natural languages, carrying out logical commands, participation in chess logic games, diagnosis and expertise. Analyzing the issue of artificial intelligence from the social science point of view, the human-technical relation will always be at the forefront. The common area for social and computer science are the sources and methods of machine learning. The ability of machines to learn is based on expanding knowledge and refining their behavior based on experience already acquired. The basis of machine learning is the process of induction, that is, drawing conclusions and generalizations upon given examples. The machine learning process relies on the use of a training algorithm, based on specific data in order to create a model. A method of inductive learning is called supervised learning, which is generally used to classify examples and unsupervised learning, most often used to discover structures (e.g. clusters, regularities) occurring in the analyzed data. (Russell and Norvig, 2003). 
A rapid acceleration of research on the functioning methods of artificial intelligence is the consequence of an intense technological development in the 1990s is. The first software packages were designed at the time, engineered to build up knowledge bases using a certain type of inference mechanisms. The models of expert systems, whose inference mechanisms translate into procedures resulting from a diagnosis of expert knowledge, are constantly being improved. In the decision-making systems with a high dynamics of variation, artificial neural networks are being applied, as exemplified by decision support systems in brokerage offices, stock exchanges, and banks.

The influence of artificial intelligence's functioning methods on social life has become more and more important, as well as increasingly noticeable in the global economy system. The analysis of selected global Al development programs conducted in 2018 by Digital Poland Foundation allows us to perceive a diverse motivation to develop the strategy for the most important countries in the world. In France, among other things, it was maintaining a leading role in science and the development of basic research around Al, in China - maintaining national security and order along with monitoring the citizens' behavior, and in Japan, it was maintaining a leading position in robotics, increasing industrialization and supporting the aging population. Based on the analysis of Al development strategies in 6 countries (USA, Great Britain, France, United Arab Emirates, Canada and Japan) and some selected international organizations, it is also possible to synthesize key factors impacting the development of $\mathrm{Al}$ in a given country. The authors of the report characterize the world's best centers for Al innovation and development as centers promoting a knowledge-based economy, aiming at cooperation and collaboration, as well as exchange of experience, and at the same time providing support for the initiative from the government at the municipal and local level. In these special innovative environments supported by the proprietary legislation, all kinds of experimentation and pilot projects are being launched, as well as creative solutions enabled from the ELSE area. And all this is accessible due to data availability and the facilitation of the data exchange process. Also, there is a general public concession and acceptance of the modern technologies use and work automation. At the same time, respecting intellectual property has become the appropriate standard, as well as the social acceptance of failure, manifesting itself, among other things, in the culture of innovation. And what is more, a support is provided through comprehensive financing (VC, accelerators, scale-ups, spin-offs, grants, central, municipal, federal budget). A profound awareness of decision-makers is expressed in promoting deep integration of the world of science and research with business, while commercializating the effects of their work. At the same time, most strategies assume the availability of training and a comprehensive approach to learning and education, including running a breeding ground for the new talents. The key element of any Al development strategy should be a cooperation between the government, research centers and the private sector, but also cooperation at the international level (Digital Poland Foundation, 2018).

\section{CONCLUSIONS - QVO VADIS HOMINE?}

The increasing use of artificial intelligence in the development of innovation and the learning process lead to certain social consequences. And that very fact creates enormous possibilities but also threats, and certainly will completely transform our civilization. Research in this field, however, most often comes down to technical or IT 
issues, while the greatest minds of our times: Gates, Musk and Hawking warn us against developing such an autonomous artificial intelligence model that will be capable of improving itself constantly. Because if that is the case, the most serious potential threat will be posed by Al exceeding the level of human intelligence and reaching the level of unimaginable development. The reasons for action of such an entity could not be understood then. Technical objects can then gradually take control of the environment and human behavior.

The most controversial is the use of artificial intelligence in the army [armed forces], from rockets or jets to all kinds of infrastructure control systems. At this stage, it is assumed that people are in control, not threatened by computers deciding anything themselves. It will be this way until the artificial intelligence begins to modify its goals. Even if it is possible for the machine to become self-conscious, it will still have to set tasks for itself and find a justification for them, and that part is not immediately obvious. At the moment, intelligent technologies assist us with acquiring knowledge quickly, learning new behaviors outside the traditional system of education, which, however, should not be completely eliminated. A constant reflection, inherently sociological, should accompany these technological changes, for the algorithms behind ethical actions are the very traits of humanity and it is quite difficult to assume that the machine will accept them or will develop them itself without error of proper access path.

\section{ACKNOWLEDGEMENTS}

This paper has been financially supported by University of Ostrava, Institutional Development Project (IRP) No. 201819 Social and Cultural Mechanisms of In - and Exclusion: a Comparative Perspective.

\section{REFERENCES}

BDI, 2016. Alexander von Humboldt Institut für Internet und Gesellschaft, Schlüsselresource Wissen: Lernen in einer digitalisierten Welt. Berlin.

Buchen, I. 2018. Veränderungen in der Didaktik durch Mobile Learning. In: de Witt, C., Gloerfeld, C. (ed.) Handbuch Mobile Learning. Springer VS, Wiesbaden. pp. 43-62. DOI: 10.1007/978-3-658-19123-8_3.

de Witt, C. 2018. Mobile Learning - Smart Learning - Next Learning. Prämissen für die Zukunft von Bildung. In: de Witt, C., Gloerfeld, C. (ed.) Handbuch Mobile Learning. Springer VS, Wiesbaden. pp. 995-1014. DOI: 10.1007/978-3-65819123-8_3.

Drucker, P. F., 1994. Post-Capitalist Society. New York: Harper Business.

Drucker, P. F., 1999. Knowledge-Worker Productivity. The Biggest Challenge. In: California Review Management, Vol. 41/2, pp. 79-94.

European Commission, 2018. Council Recommendation on Key Competencies for Lifelong Learning. Brussels.

Foucault, M., 1988. Technologies of the Self. In: Martin, L. H., Gutman, H., Hutton, P. $\mathrm{H}$. (ed). Technologies of the Self. A Seminar with Michel Foucault. London: Tavistock Publications. pp. 16-49.

Glahn, C., Gruber, M. R., Tartakovski, O. 2015. Beyond Delivery Modes and Apps: A Case Study on Mobile Blended Learning in Higher Education. In: Design for Teaching and Learning in a Networked World: 10th European Conference on Technology Enhanced Learning, EC-TEL 2015, Toledo, Spain, September 15 - 18, 
2015, Proceedings. pp. 127-140, Springer Publishing International. DOI: 10.1007/978-3-319-24258-3_10

Kerres, M., de Witt, C., Statmann, J., 2002. Didaktische Konzepte für erfolgreiches Lernen. In: Schwuchow, K., Guttmann, J. (ed). Jahrbuch Personalentwicklung \& Weiterbildung 2003 München: Luchterhand Verlag, pp. 3-14.

Marcuse, H., 1941. Some Social Implications of Modern Technology. In: Studies in Philosophy and Social Sciences, Vol. 9, No. 3, pp. 414-439.

Marcuse, H., 1964. One-Dimensional Man. Studies in the Ideology of Advanced Industrial Societies. London: Routledge \& Keagan Paul. UK.

Micklethwait, J., Wooldridge A., 1996. The witch doctors: making sense of the management gurus. New York: Times Books., USA.

Nonaka I., Takeuchi H., 1995, The knowledge creating company: how Japanese companies create the dynamics of innovation, New York: Oxford University Press, USA

Przegląd Strategii Rozwoju Sztucznej Inteligencji na Świecie 2018. Fundacja Digital Poland, Wydanie I, Warszawa, Poland.

Russell S. J., Norvig P., 2003. Artificial Intelligence: A Modern Approach, Prentice Hall, New Jersey, USA.

Senge P. M., 1990. The Fifth Discipline: The art and practice of the learning organization, Doubleday, New York, USA.

Suchacka M., 2014. Transformacja regionu przemysłowego $w$ kierunku regionu wiedzy. Studium socjologiczne województwa śląskiego, Wydawnictwo Uniwersytet Śląski, Katowice, Poland.

Suchacka M., Szczepański M. S., 2006. Kultura organizacji uczącej się. Mit, fakt czy przyszłość, Humanizacja Pracy, (XXXXIX), Szkoła Wyższa im. P. Włodkowica w Płocku, T.4-5 (232-233) pp. 9-21, Poland.

Turing, A. M., 1950. Computing machinery and intelligence. In: Cooper S.B., Van Leeuwen J., 2013, (eds.) Alan Turing His Work And Impact, Elsevier Inc. Amsterdam, The Netherlands.

Urciuoli, B., 2008. Skills and Selves in the New Workplace. In: American Ethnologist, Vol. 35, No. 2, pp. 211-228. DOI: 10.1111. USA. 